\title{
The Effect of Packaging Shape on the Distribution of Electric and Magnetic Fields and SAR Induced in 3D Models of Water Containers
}

\author{
Maher A. A. Abdelsamie1, Russly B. Abdul Rahman1,2,3, Shuhaimi Mustafa1, \\ Dzulkifly Hashim 1 \\ ${ }^{1}$ Halal Products Research Institute, Universiti Putra Malaysia, Serdang, Malaysia \\ ${ }^{2}$ Department of Process \& Food Engineering, Faculty of Engineering (UPM), Serdang, Malaysia \\ ${ }^{3}$ Faculty of Food Science \& Technology, University Putra Malaysia (UPM), Serdang, Malaysia \\ Email: mabdelaleem2011@gmail.com, russly@upm.edu.my
}

Received 30 June 2014; revised 25 July 2014; accepted 12 August 2014

Copyright (C) 2014 by authors and Scientific Research Publishing Inc.

This work is licensed under the Creative Commons Attribution International License (CC BY). http://creativecommons.org/licenses/by/4.0/

(c) (i) Open Access

\begin{abstract}
In this study, two software packages using different numerical techniques-FEKO 6.3 with FiniteElement Method (FEM) and XFDTD 7 with Finite Difference Time Domain Method (FDTD)-were used to assess exposure of 3D models of square-, rectangular-, spherical- and pyramidal-shaped water containers to electromagnetic waves at 300, 900, and $2400 \mathrm{MHz}$ frequencies. Using the FEM simulation technique, the peak electric field of $25,4.5,3$, and $2 \mathrm{~V} / \mathrm{m}$ at $300 \mathrm{MHz}$ and 15.75, 1.5, 1.8 and $1.75 \mathrm{~V} / \mathrm{m}$ at $900 \mathrm{MHz}$ were observed in pyramidal-, rectangular-, spherical-, and squareshaped 3D container models, respectively. The FDTD simulation method confirmed a peak electric field of 12.782, 10.907, 0.81867 and $10.625 \mathrm{~V} / \mathrm{m}$ at $2400 \mathrm{MHz}$ in the pyramidal-, square-, spherical-, and rectangular-shaped 3D models, respectively. The study demonstrated an exceptionally high level of electric field in the water in the two identical pyramid-shaped 3D models analyzed using the two different simulation techniques. Both FEM and FDTD simulation techniques indicated variations in the distribution of electric, magnetic fields, and specific absorption rate of water stored inside the 3D container models. The study successfully demonstrated that shape and dimensions of 3D models significantly influence the electric and magnetic fields inside packaged materials; thus, specific absorption rates in the stored water vary according to the shape and dimensions of the packaging materials.
\end{abstract}

\section{Keywords}

SAR, EM Simulation, Shape Effect, FDTD, FEM 


\section{Introduction}

Over the last few decades, mobile communication devices have completely changed the way we connect with our community. It is no exaggeration to say that modern civilization thrives on our ability to communicate easily using the Internet and mobile devices. However, most of our communication techniques use radio frequency (RF), exposing every biological and nonbiological entity to RF electromagnetic radiation from cellular towers and mobile devices. In fact, we are exposed to electromagnetic radiation at every possible frequency. For example, WI-LAN technology on the Internet and home or office networks use microwaves in the range of 2 - 4 GHz. Bluetooth technology connects our devices, and Wi-Fi technology allows us to remain connected over longer distances. We also use WiMAX technology to communicate over very long distances, ranging from 10 - 20 kilometers [1]. With increasingly demand for communication, we are progressively installing more and more base stations throughout the world.

Recently, some studies have highlighted the health hazards caused by electromagnetic fields (EMs). These health issues have concerned many professionals and the health-conscious public. This concern spurred many researchers to study the effects of electromagnetic fields on biological materials, particularly the absorption rate of electromagnetic radiation when a human body or other biological objects are exposed to such radiation [2]-[14]. Finite element method FEM and finite-difference time-domain FDTD numerical techniques were also used in many studies to investigate the effect of exposure of food and food packages to electromagnetic field in the microwave frequency range [15]-[20]. The exposure of biological materials to radio waves induces internal electric and magnetic fields, which can be solved using Maxwell's equations for given boundary conditions [21]. It has been observed that EM fields lead to a rise in temperature because biological materials exposed to electromagnetic radiation absorb significant amounts of energy. The term "Specific Absorption Rate" (SAR) is used to define this rate of energy absorption in biological objects. Government regulations and radiation exposure guidelines use the SAR to define safe limits of exposure to high-frequency EM fields for occupational workers as well as the general public. Specific absorption rate has been standardized as watts per kilogram [22]. However, the guidelines and regulations mainly revolve around the thermal effects of microwave radiation. There is sufficient evidence to prove that non-thermal effects also deteriorate our health and well-being; unfortunately, current regulations are not effective enough to prevent non-thermal health hazards of electromagnetic radiation [23]. Numerous dosimetric studies have intensively used numerical SAR calculations to evaluate the effects of exposure to EM radiations from communication towers and other mobile devices on human tissues [24] [25]. A study on EM radiations and its effects on water has also been conducted [26]. All these studies provide valuable information about the thermal effects of electromagnetic radiation, demonstrating how rises in temperature through electromagnetic radiation affect our tissues and other biological materials.

Over the last few decades, a number of studies were carried out to understand the effects of energy fields reinforced inside pyramidal and other geometrical shapes [27]-[37]. Influenced by this shape-effect phenomenon, one study used flux gate magnetometer measurements to demonstrate that pyramidal-shaped structures made of fiberglass actually induce magnetic fields [35]. A special sensor was developed by an electronic engineer to measure the energy that flows from the pyramidal structure [35]. It was observed that the reinforced energy fields within the pyramidal structure provide several benefits: changes in the $\mathrm{pH}$ value of stored materials, increased moisture loss of biological samples, and almost three times quicker decomposition ratio of $\mathrm{H}_{2} \mathrm{O}_{2}$ or aqueous hydrogen peroxide [34]. A recent study demonstrated that in comparison to other control samples, pyramidal structures can be more effective in controlling growth of microorganisms in milk [30]. Another study demonstrated the role of pyramidal-shaped packages in improving the quality of packaged water through changing the water structure by forming filament-shaped crystals. This study demonstrated that pyramidal-shaped packages significantly reduce solid substrate-bound crystals and prevent scale formation so that water quality gradually improves [28].

To analyze the effect of shape and dimension on the distribution of electric and magnetic fields and specific absorption rate SAR, a recent study used different shapes of human head models — such as flat, spherical, and ellipsoidal-to evaluate the changes in specific absorption rate induced by the different shapes of human heads [38]. The study confirmed that the shapes of our heads significantly affect the amount of energy absorbed from the environmentally abundant electromagnetic radiation at $900 \mathrm{MHz}$ frequency.

The main aim of this study is to find out how different geometrical shapes influence the distribution of electric and magnetic fields and the resulting specific absorption rate SAR of water that is sorted in pyramidal-, rec- 
tangular-, spherical-, and square-shaped packaging containers exposed to the environmentally abundant electromagnetic radiation, using both FEM and FDTD simulation methods. The specific objective was to simulate EM waves at 300, 900, and $2400 \mathrm{MHz}$ irradiated from occupational wireless communications to monitor the distribution of electric $(\mathrm{E})$ and magnetic $(\mathrm{H})$ fields and then record the specific absorption rate induced in water stored in different geometric-shaped containers.

\section{Methods}

\subsection{Experimental Setup}

Two evaluate the effects of four different shapes of packaging containers on the distribution of electric and magnetic fields in stored water and associated SARs. FEKO 6.3 was used to model four containers and simulate electromagnetic radiation at 300 and $900 \mathrm{MHz}$ frequencies. The 3D models were exported from FEKO software and imported in XFDTD 7 software to simulate the EM field at $2400 \mathrm{MHz}$. The 3D models were standing in a free space. The electric and magnetic fields and SAR of four container models was estimated at frequencies of 300, 900, and $2400 \mathrm{MHz}$ using plane wave excitation with $1 \mathrm{~V} / \mathrm{m}$ magnitude.

\subsection{SAR Calculation}

SAR provides a measure of electromagnetic radiation that is absorbed by any biological object. It has become a crucial dosimetric variable for evaluating the effects of electromagnetic radiation from a wide range of frequencies, $100 \mathrm{KHz}$ to $10 \mathrm{GHz}$. SAR can be calculated in the following manner [39]:

$$
S A R=\frac{\sigma|E|^{2}}{\rho}(\mathrm{W} / \mathrm{kg})
$$

$\sigma=$ electric conductivity of biological object in $\mathrm{S} / \mathrm{m}$;

$\rho=$ mass density in $\mathrm{kg} / \mathrm{m}^{3}$;

$E=$ root-mean-square (rms) magnitude of the electric field strength in $\mathrm{V} / \mathrm{m}$.

The database of dielectrics from FEKO 6.3 and XFDTD7 libraries served as the main sources of reference.

\section{Modeling}

In this study, the FEKO 6.3 software-based on FEM [40]—was used to construct 3D models of pyramidal-, rectangular-, spherical-, and square-shaped containers with nearly the same volume, all $100 \%$ filled with water (Figures 1(a)-(d)). Each modeled container consisted of three parts: 1) polymethylemetacrylate or PMMA with $3 \mathrm{~mm}$ thickness serving as the external layer, 2) high-density polyethylene or HDPE with $0.02 \mathrm{~mm}$ thickness as the internal layer, and 3) water as the inner medium. The dimensions of the four containers are described in Table 1. The various software configuration parameters-such as the electrical properties of Water, HDPE and PMMA used for simulation-are described in Table 2. The conductivity and dielectric constant of external and internal layers reflect their capacitance and energy storage capabilities [40]. To simulate the electromagnetic radiation in the modern living environment, a broad range of frequencies (ranging from $300 \mathrm{MHz}-2.4 \mathrm{GHz}$ ) were simulated. The configuration of the computer for conducting simulation consisted of a dual-core $2.9 \mathrm{GHz}$ processor with 8 GB RAM. However, the maximum possible configuration parameters of the system served as the maximum limits of upper frequency ranges. FEKO simulated frequencies up to $900 \mathrm{MHz}$, and then the FEKO 3D models exported and imported to XFDTD software to simulate the frequency ranges of $2.4 \mathrm{GHz}$. Electromagnetic radiation contains both electric and magnetic fields that oscillate in a fixed relationship, perpendicular to each other and perpendicular to the direction of energy and propagation of waves. Having different dimensions, the four containers influence electromagnetic waves in an entirely different manner, inducing changes in electric and magnetic fields inside and around the containers. The simulation was carried out to determine various study parameters (e.g., electric and magnetic fields distribution, and maximum SAR values) to compare the results from the four container models and analyze the results in light of other scientific studies.

\subsection{FEKO Model}

Based on the FEM method, FEKO provides better results for electrically large and dielectric bodies. The vo- 


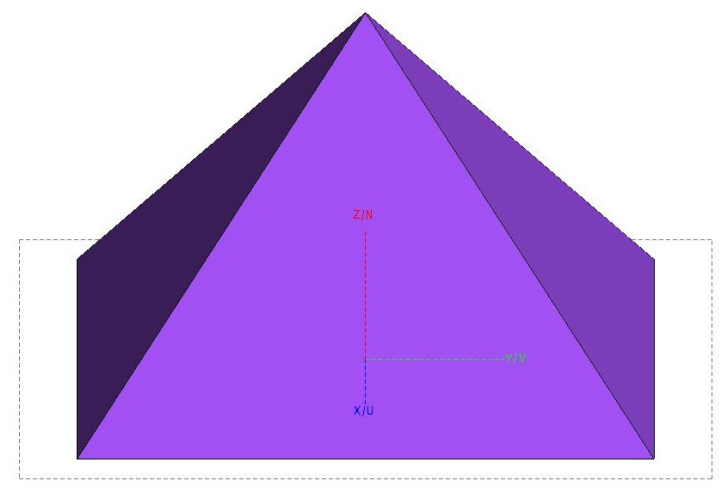

(a)

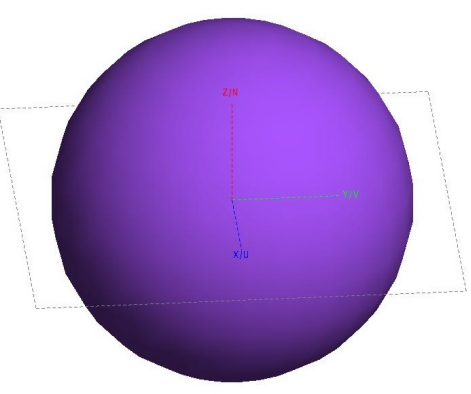

(c)

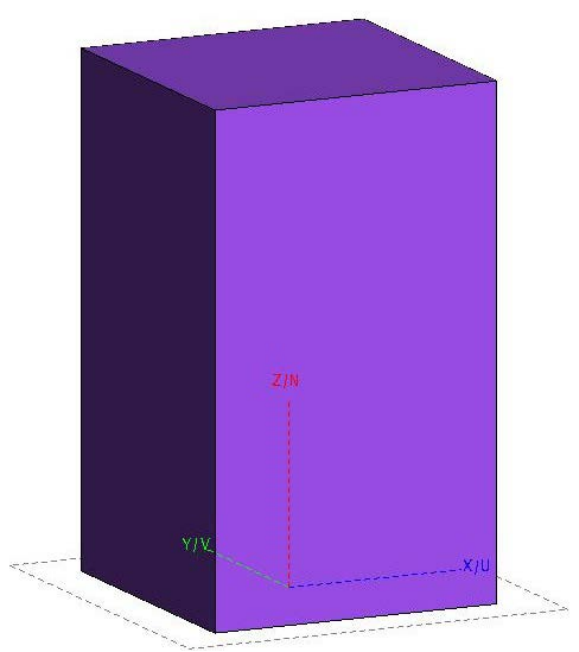

(b)

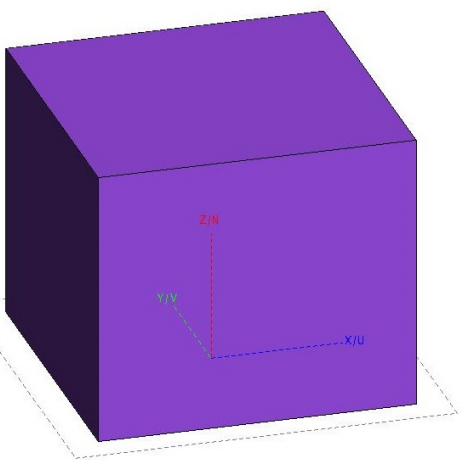

(d)

Figure 1. (a) 3D model of pyramid-shaped container; (b) 3D model of rectangle-shaped container; (c) 3D model of sphericalshaped container; (d) 3D model of square-shaped container.

Table 1. Dimensions of spherical-shaped, pyramid-shaped, square-shaped, and rectangular-shaped containers.

\begin{tabular}{|c|c|c|c|c|}
\hline \multirow{2}{*}{ Container } & \multicolumn{3}{|c|}{ Dimensions } & \multirow[b]{2}{*}{ Height (mm) } \\
\hline & Width (mm) & Depth (mm) & Radius (mm) & \\
\hline Spherical-shaped container & - & - & 88.8 & - \\
\hline Pyramid-shaped container & 242.362 & 242.362 & - & 155.10 \\
\hline Rectangle-shaped container & 120 & 120 & - & 205.83 \\
\hline Square-shaped container & 150 & 150 & - & 131.23 \\
\hline
\end{tabular}

lume-meshing technique of FEM uses tetrahedral elements for meshing arbitrarily shaped heterogeneous volumes with extreme accuracy. The standard mesh was applied for $300 \mathrm{MHz}$ frequency, and the custom mesh with 6.405 tetrahedral edge length was applied for $900 \mathrm{MHz}$. The simulation was carried out using linear plane wave excitation and the finite element method (FEM). To excite the surface of the four containers from one side, a single incident wave with magnitude of $1 \mathrm{~V} / \mathrm{m}$ and $45^{\circ}$ angle was generated at frequencies of $300 \mathrm{and} 900 \mathrm{MHz}$. Near-field calculations were performed to analyze the distribution of electric (E) and magnetic (H) fields 
Table 2. Electrical properties of PMMA, HDPE, and water.

\begin{tabular}{cccccc}
\hline Material & \multicolumn{5}{c}{ Prameter } \\
& \multicolumn{1}{c}{$\begin{array}{c}\text { Evaluation } \\
\text { frequency } \mathrm{MHz}\end{array}$} & $\begin{array}{c}\text { Relative permittivity } \\
\varepsilon r\end{array}$ & $\begin{array}{c}\text { Conductivity } \sigma(\mathrm{S} / \mathrm{m}) \\
\text { Mass density } \rho \\
\left(\mathrm{kg} / \mathrm{m}^{3}\right)\end{array}$ & $\begin{array}{c}\text { Dielectric } \\
\text { Loss tangent tan } \delta\end{array}$ \\
\hline PMMA $^{\text {a }}$ & 300 & 2.6 & 0.000247342 & 1190 & 0.0057 \\
PMMA $^{\mathrm{a}}$ & 900 & 2.6 & 0.000742026 & 1190 & 0.0057 \\
PMMA $^{\mathrm{a}}$ & 2400 & 2.6 & 0.00197874 & 1190 & 0.0057 \\
HDPE $^{\mathrm{b}}$ & 300 & 2.26 & $1.16928 \mathrm{e}-05$ & 970 & 0.00031 \\
HDPE $^{\mathrm{b}}$ & 900 & 2.26 & $3.50785 \mathrm{e}-05$ & 970 & 0.00031 \\
HDPE $^{\mathrm{b}}$ & 2400 & 2.26 & $9.35427 \mathrm{e}-05$ & 970 & 0.00031 \\
Water $^{\text {Water }}$ & 300 & 80.4 & 0.210671 & 1000 & 0.157 \\
Water & 900 & 80.4 & 0.632014 & 1000 & 0.157 \\
\hline
\end{tabular}

${ }^{\mathrm{a}}$ Polymethyl methacrylate (PMMA); ${ }^{\mathrm{b}}$ High-density polyethylene (HDPE).

within the four containers. In addition, maximum SAR were calculated to measure the amount of energy or electromagnetic radiation absorbed by the water stored in the four containers. Thus, FEKO simulation allowed the study of E, H, and SAR distribution up to $900 \mathrm{MHz}$; to study the E, $\mathrm{H}$ and SAR distribution for higher frequency ranges of $2400 \mathrm{MHz}$, another simulation using XFDTD 7 software was conducted.

\subsection{XFDTD Model}

The XFDTD7 software package is very useful for studying three-dimensional finite difference time domains [41]. Based on the FDTD method, this package provides full-wave time-domain solutions for Maxwell's equations. This robust technique is known for its accuracy. Features such as graphical user interface and automatic calculation of E, H and SAR distributions make it a versatile simulation software. It can simulate physical structures under observation by using a mesh of cells; this is the key feature of this FDTD-based model. The entire process involved four basic steps: 1 ) importing the 3D geometry, 2) creating the mesh, 3) defining the parameters, and 4) running the process for final results. In this study, XFDTD 7 software was used to simulate and obtain E, H and SAR distributions from higher frequency electromagnetic radiations up to $2400 \mathrm{MHz}$.

\section{Results and Discussion}

Using FEM with standard mesh at $300 \mathrm{MHz}$ and coarse mesh at $900 \mathrm{MHz}$, the distribution of the electric, magnetic, and SAR of the four container models is presented in Figures 2(a)-(c), Figures 3(a)-(c), Figures 4(a)-(c), Figures 5(a)-(c), Figures 6(a)-(c), Figures 7(a)-(c), Figures 8(a)-(c) and Figures 9(a)-(c).

Significant variations in the electric field of the four containers was observed during the study: The electric field induced in water stored inside the pyramidal-shaped package reached the highest levels ( 25 and $15.75 \mathrm{~V} / \mathrm{m}$ ) at 300 and $900 \mathrm{MHz}$ respectively (Figure 2(a) and Figure 3(a)), followed by the rectangular-shaped container with 4.5 and $1.5 \mathrm{~V} / \mathrm{m}$ at 300 and $900 \mathrm{MHz}$, respectively (Figure 4(a) and Figure 5(a)), then the sphericalshaped container with 3 and $1.8 \mathrm{~V} / \mathrm{m}$ at 300 and $900 \mathrm{MHz}$, respectively (Figure 8(a) and Figure 9(a)), and the square-shaped container with 2 and $1.75 \mathrm{~V} / \mathrm{m}$ at 300 and $900 \mathrm{MHz}$, respectively (Figure 6(a) and Figure 7(a)). Although the peak level of the magnetic field induced in water stored inside the rectangular-shaped container model reached $25 \mathrm{~mA} / \mathrm{m}$ at $300 \mathrm{MHz}$ (Figure 4(b)) compared to $20 \mathrm{~mA} / \mathrm{m}$ in both pyramidal-shaped and square-shaped container models (Figure 2(b) and Figure 6(b)), the pyramidal-shaped and spherical-shaped container models produced the highest magnetic field of 18 and $25 \mathrm{~mA} / \mathrm{m}$ at $900 \mathrm{MHz}$, respectively (Figure 3(b) and Figure 9(b)), compared to 12.5 and $16.5 \mathrm{~mA} / \mathrm{m}$ (Figure 5(b) and Figure 7(b)) for rectangular-shaped and square-shaped container models, respectively.

The maximum SARs in water were identical: $90 \mu \mathrm{W} / \mathrm{kg}$ at $900 \mathrm{MHz}$ for pyramidal-shaped, rectangular-shaped, and square-shaped container models (Figure 3(c), Figure 5(c), and Figure 7(c)). Although the maximum 


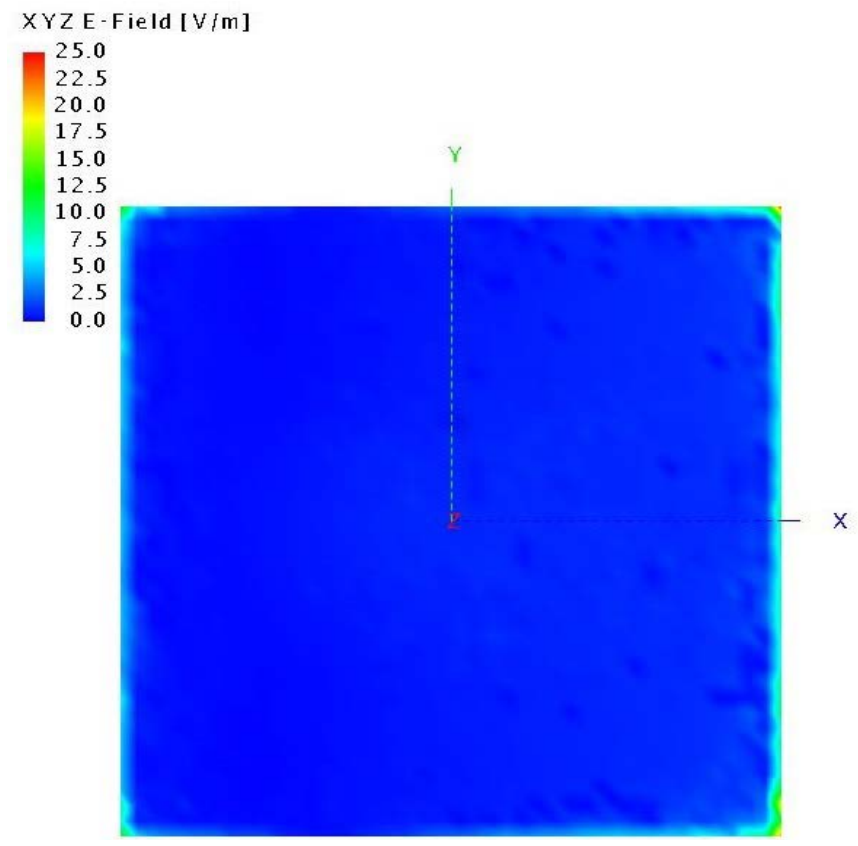

(a)

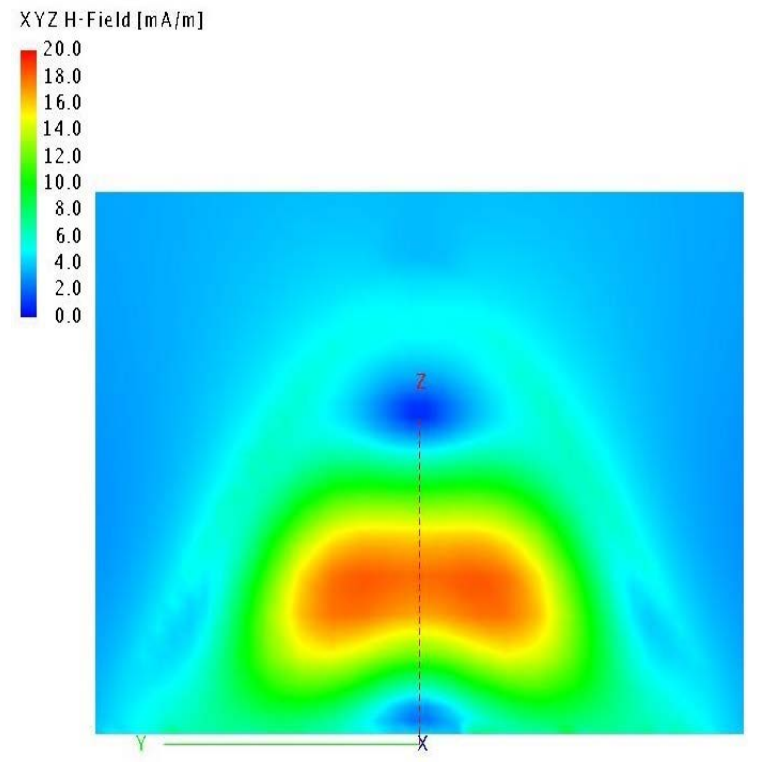

(b)

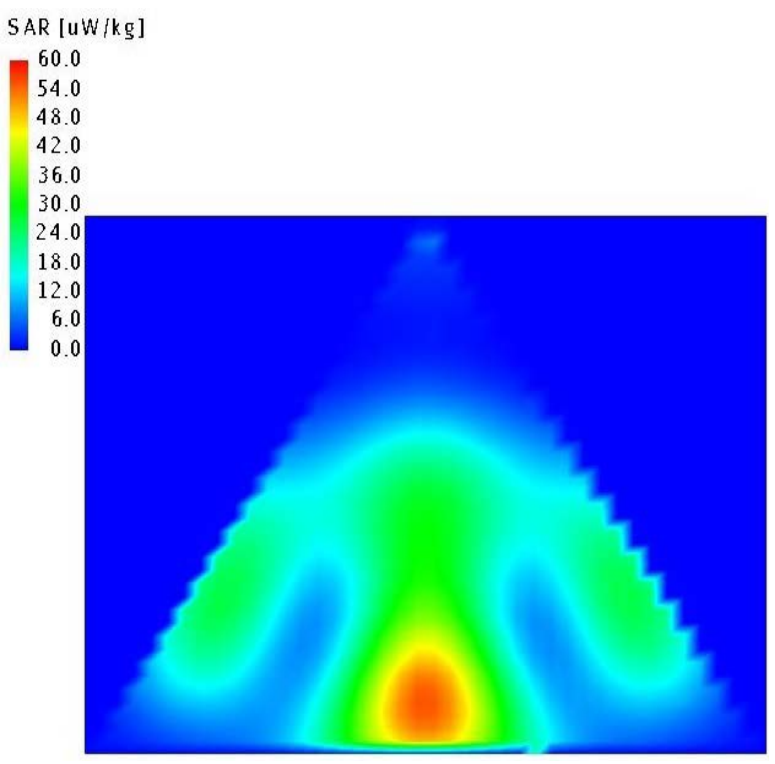

(c)

Figure 2. (a) Electric field distribution of xy surface of water stored inside pyramid-shaped container at $300 \mathrm{MHz}$; (b) Magnetic field distribution of xy surface of water stored inside pyramid-shaped container at $300 \mathrm{MHz}$; (c) Maximum SAR distribution of xy surface of water stored inside pyramid-shaped container at $300 \mathrm{MHz}$.

SARs reached 175 and $225 \mu \mathrm{W} / \mathrm{kg}$ in the rectangular-shaped and spherical-shaped containers at $300 \mathrm{MHz}$ and $900 \mathrm{MHz}$, respectively (Figure 4(c) and Figure 9(c)), the maximum SAR was $54 \mu \mathrm{W} / \mathrm{kg}$ in spherical-shaped container (Figure 8(c)) at $300 \mathrm{MHz}$ and it was identical $60 \mu \mathrm{W} / \mathrm{kg}$ in the pyramidal-shaped and square-shaped container models at $300 \mathrm{MHz}$ (Figure 2(c) and Figure 6(c)).

Using FDTD at $2400 \mathrm{MHz}$, the distribution of the electric fields, magnetic fields, and SAR of the four container models are presented in Figures 10(a)-(c), Figures 11(a)-(c), Figures 12(a)-(c) and Figures 13(a)-(c). Considerable variations in the electric and magnetic fields of the four container models were observed at 2400 $\mathrm{MHz}$ frequency. The electric field induced in the water stored in the pyramidal-shaped container model again 


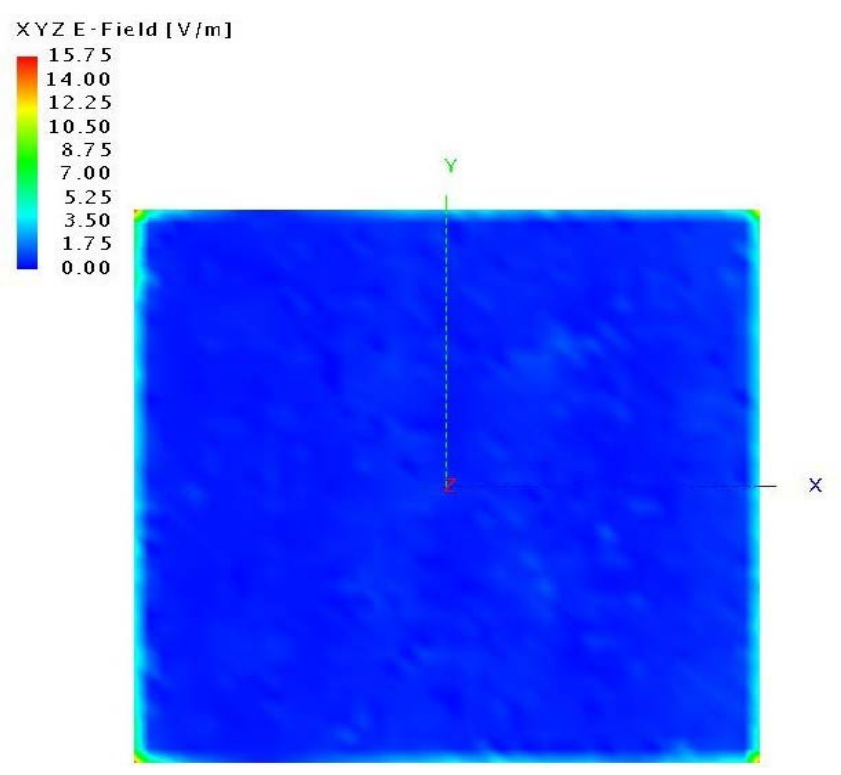

(a)

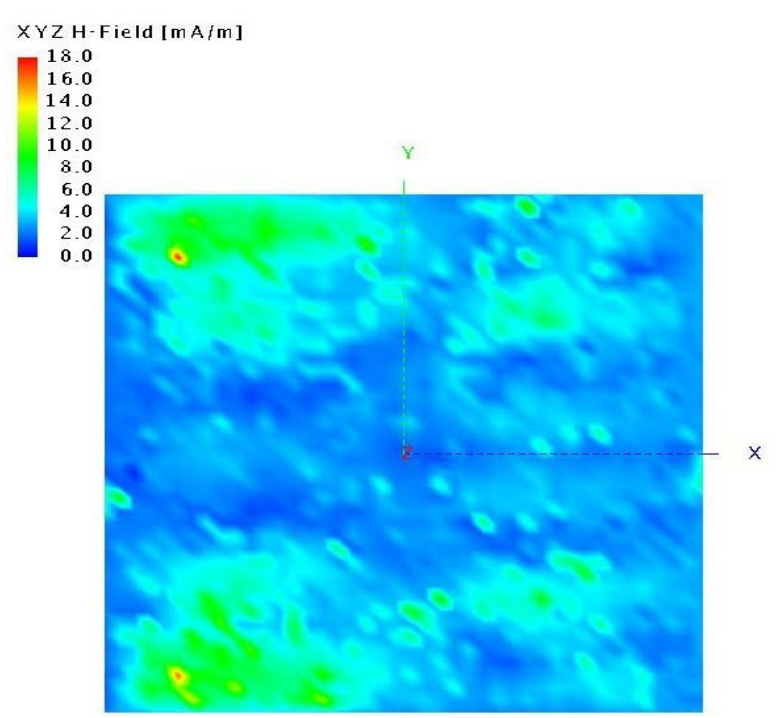

(b)

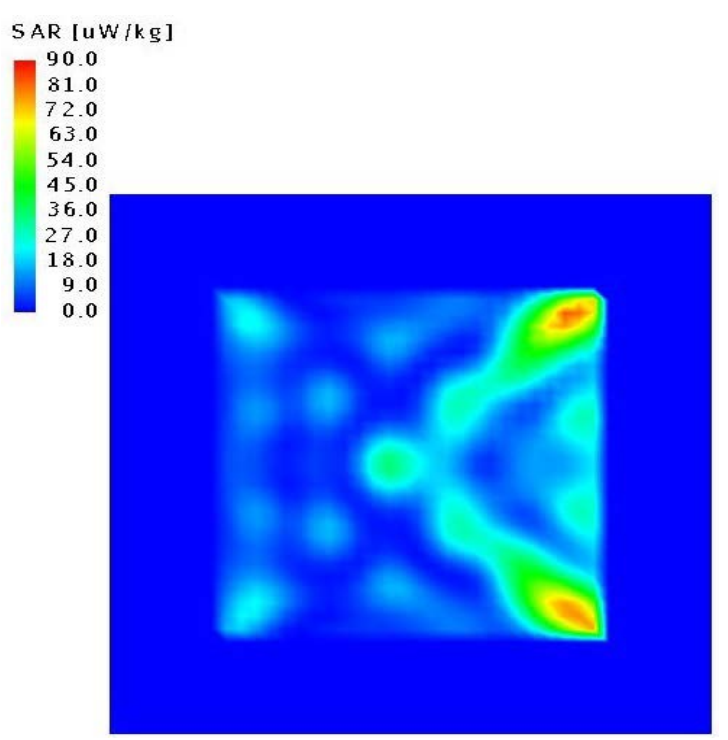

(c)

Figure 3. (a) Electric field distribution of xy surface of water stored inside pyramid-shaped container at $900 \mathrm{MHz}$; (b) Magnetic field distribution of xy surface of water stored inside pyramid-shaped container at $900 \mathrm{MHz}$; (c) Maximum SAR distribution of xy surface of water stored inside pyramid-shaped container at $900 \mathrm{MHz}$.

reached the highest levels of $12.782 \mathrm{~V} / \mathrm{m}$ (Figure $\mathbf{1 0}(\mathrm{a})$ ), followed by the square-shaped model with $10.907 \mathrm{~V} / \mathrm{m}$ (Figure 12(a)), the rectangular-shaped container model with $10.625 \mathrm{~V} / \mathrm{m}$ (Figure 11(a)), and then the sphericalshaped container model with $0.81867 \mathrm{~V} / \mathrm{m}$ (Figure 13(a)). Regarding magnetic fields, the square-shaped container model topped with a magnetic field of $0.25624 \mathrm{~A} / \mathrm{m}$ (Figure 12(b)), followed by the rectangular-shaped container model with $0.25485 \mathrm{~A} / \mathrm{m}$ (Figure 11(b)), and the pyramidal-shaped container model with 0.078444 A/m (Figure 10(b)), the lowest level was the spherical-shaped container model with 0.0069309 A/m (Figure 13(b)). In the same trend, the maximum SAR $0.071744 \mathrm{~W} / \mathrm{kg}$ was observed in the square-shaped container model (Figure 12(c)), while the rectangular-, pyramidal-, spherical-shaped container models followed with 0.070817, 0.0052121 and 5.959e-05 W/kg, respectively, as shown in (Figure 11(c), Figure 10(c) and Figure 13(c)). According to both the FEM and FDTD simulation techniques results, the pyramidal-shaped container model showed the highest peak level of electric fields at 300, 900, and $2400 \mathrm{MHz}$. Due to dimensional differ- 


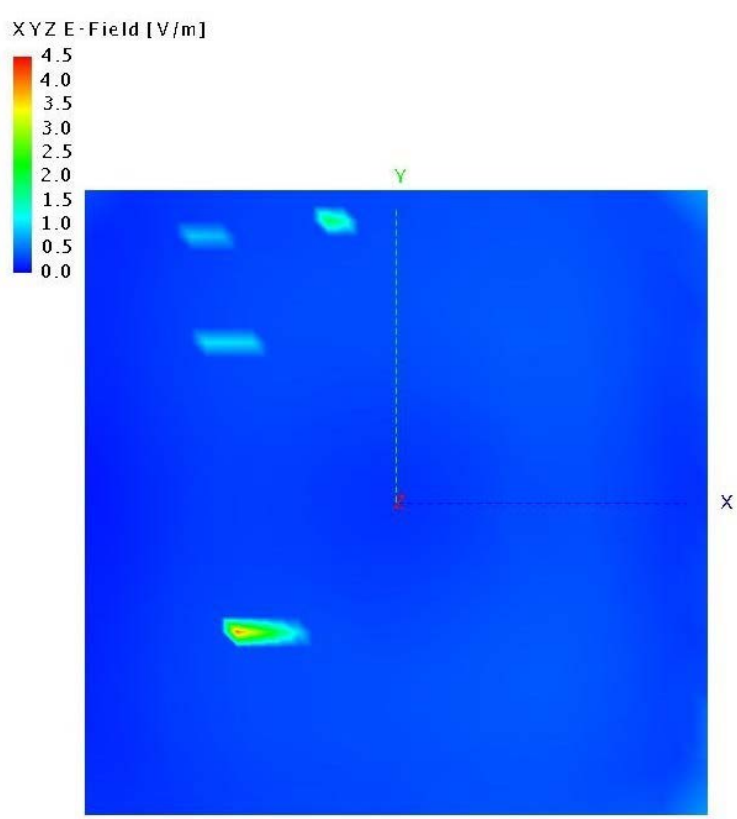

(a)

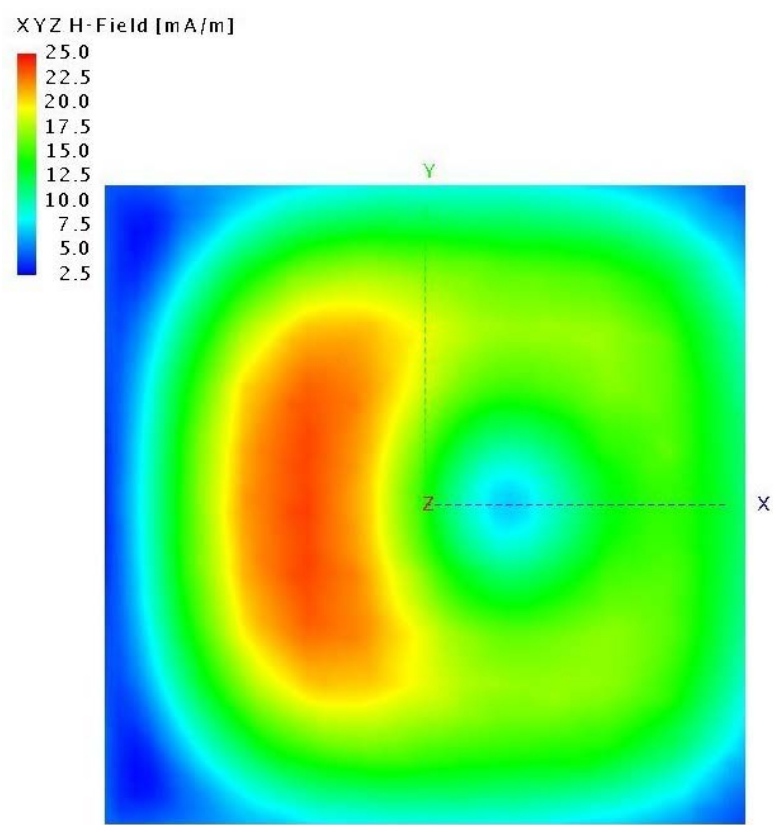

(b)

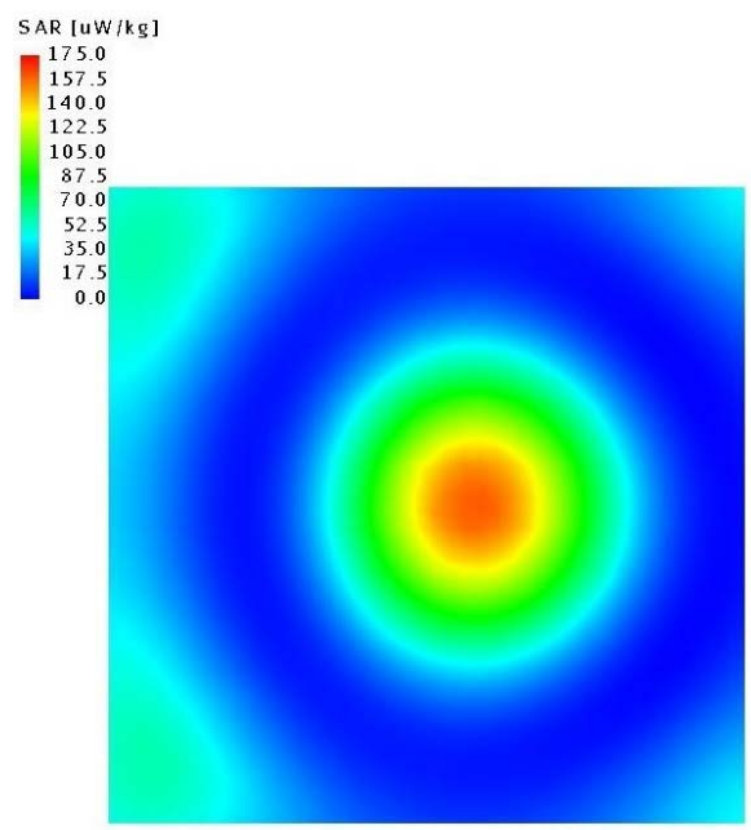

(c)

Figure 4. (a) Electric field distribution of xy surface of water stored inside rectangular-shaped container at $300 \mathrm{MHz}$; (b) Magnetic field distribution of xy surface of water stored inside rectangular-shaped container at $300 \mathrm{MHz}$; (c) Maximum SAR distribution of xy surface of water stored inside rectangular-shaped container at $300 \mathrm{MHz}$.

ences, each container might exerted a different impact on the propagation of the electromagnetic waves and thus affect the distribution of the electric and magnetic fields inside and around the containers. The slope angle of the pyramid-shaped container might affected the propagation of the electromagnetic waves, which result in an increase in the electric and magnetic fields. To rule out any inconsistencies, all the variables and configuration parameters-such as PMMA, HDPE, and water materials and their dielectric constants, dielectric loss tangent, thickness of PMMA and HDPE layers-were kept identical in all four container models. This study successfully demonstrated that shape and dimensions of packaging containers significantly influence the distribution of 


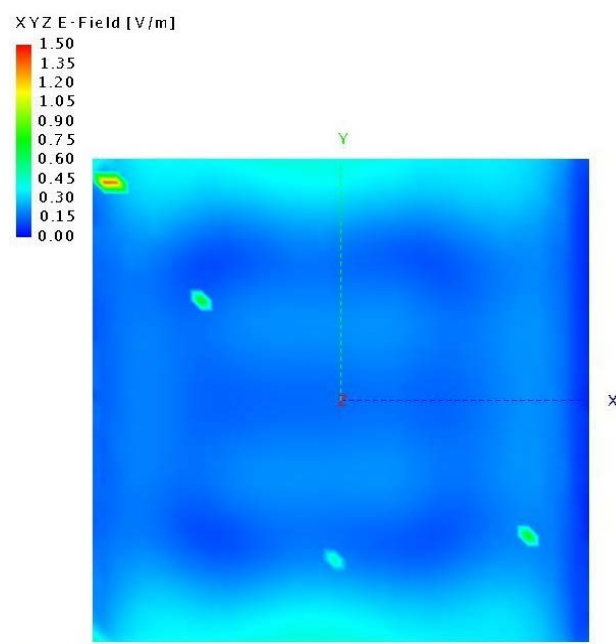

(a)

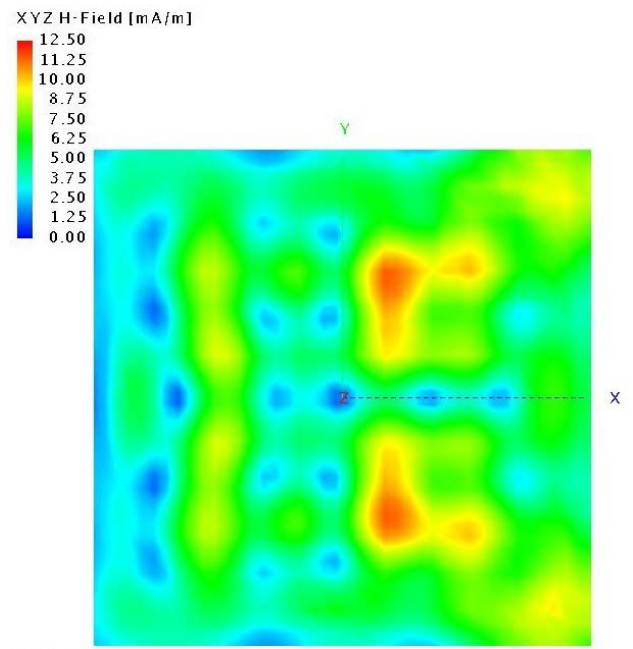

(b)

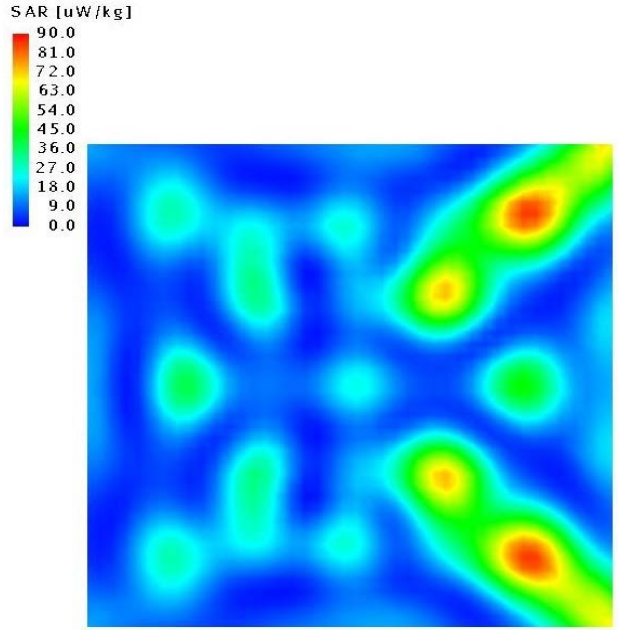

(c)

Figure 5. (a) Electric field distribution of xy surface of water stored inside rectangular-shaped container at $900 \mathrm{MHz}$; (b) Magnetic field distribution of xy surface of water stored inside rectangular-shaped container at $900 \mathrm{MHz}$; (c) Maximum SAR distribution of xy surface of water stored inside rectangular-shaped container at $900 \mathrm{MHz}$. 


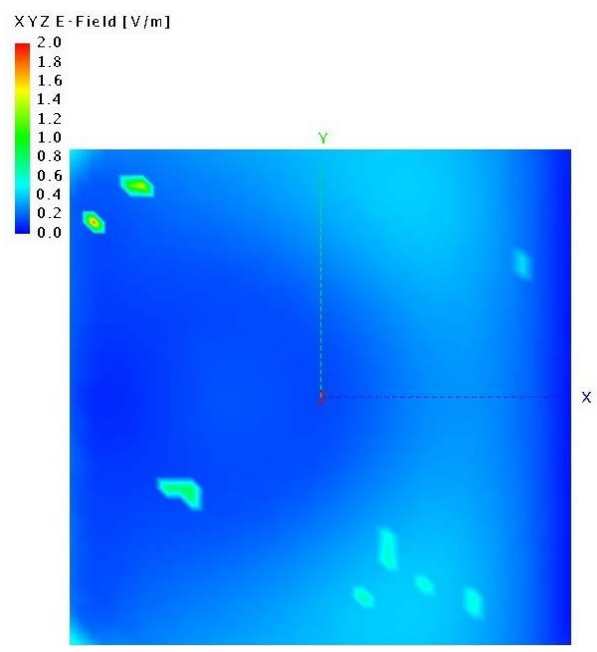

(a)

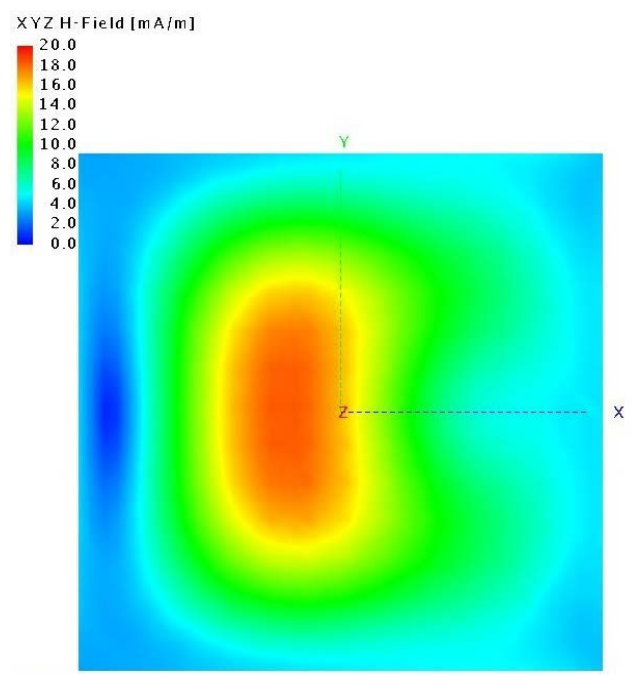

(b)

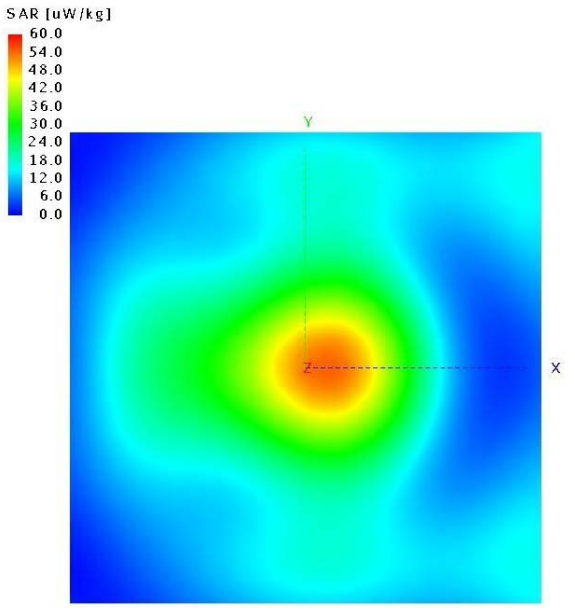

(c)

Figure 6. (a) Electric field distribution of xy surface of water stored inside square-shaped container at $300 \mathrm{MHz}$; (b) Magnetic field distribution of xy surface of water stored inside square-shaped container at $300 \mathrm{MHz}$; (c) Maximum SAR distribution of xy surface of water stored inside square-shaped container at $300 \mathrm{MHz}$. 


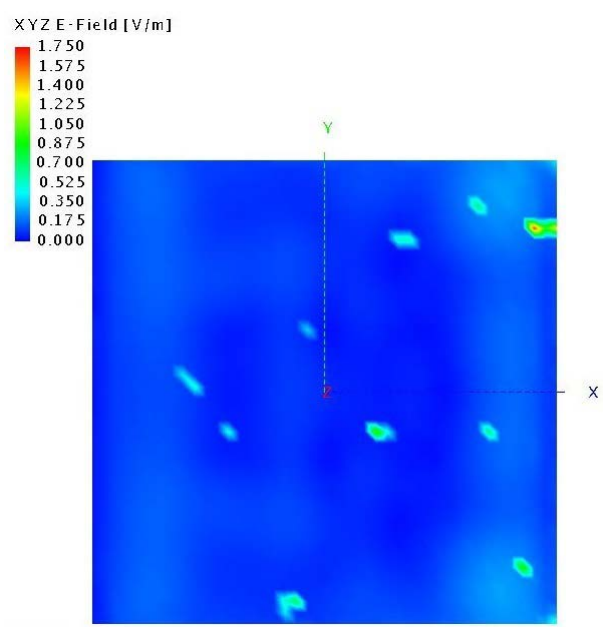

(a)

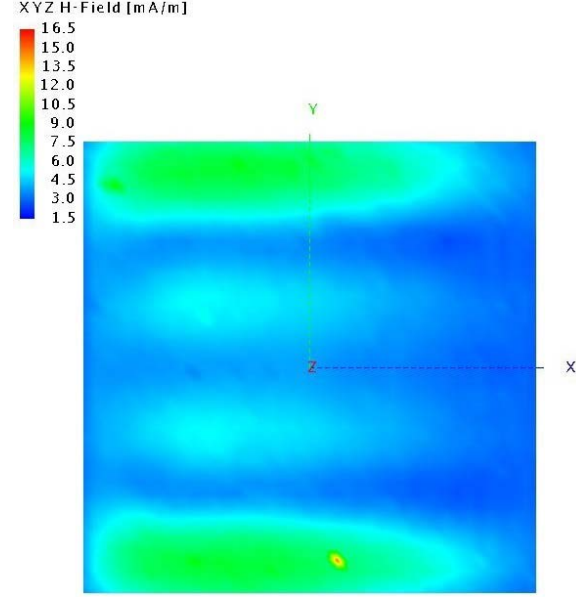

(b)

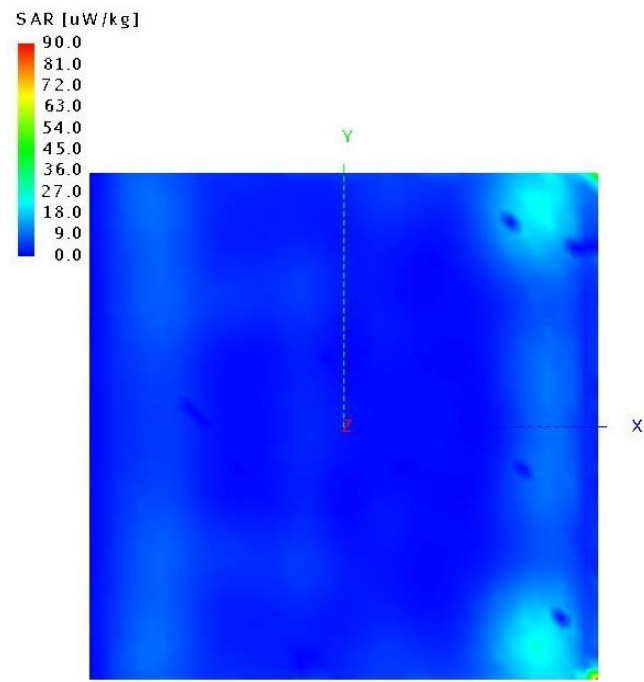

(c)

Figure 7. (a) Electric field distribution of xy surface of water stored inside square-shaped container at $900 \mathrm{MHz}$; (b) Magnetic field distribution of xy surface of water stored inside square-shaped container at $900 \mathrm{MH}$; (c) Maximum SAR distribution of xy surface of water stored inside square-shaped container at $900 \mathrm{MHz}$. 


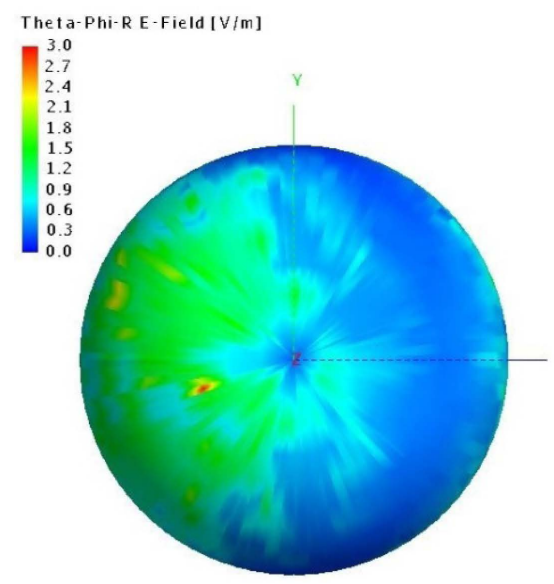

(a)

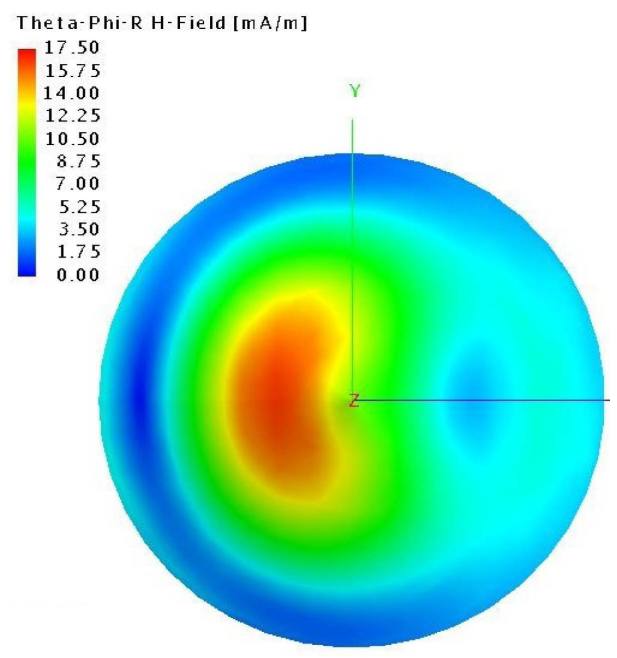

(b)

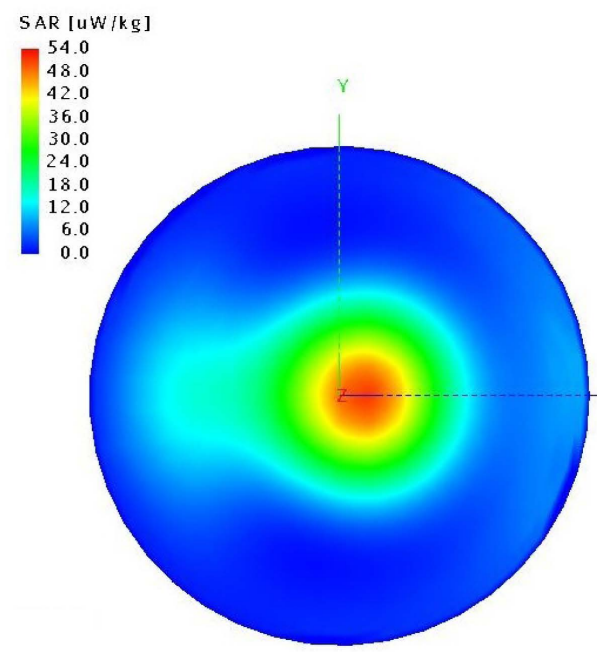

(c)

Figure 8. (a) Electric field distribution of PhiTheta-surface of water stored inside spherical-shaped container at $300 \mathrm{MHz}$; (b) Magnetic field distribution of PhiTheta-surface of water stored inside spherical-shaped container at $300 \mathrm{MHz}$; (c) Maximum SAR distribution of RPhi-surface of water stored inside spherical-shaped container at $300 \mathrm{MHz}$. 


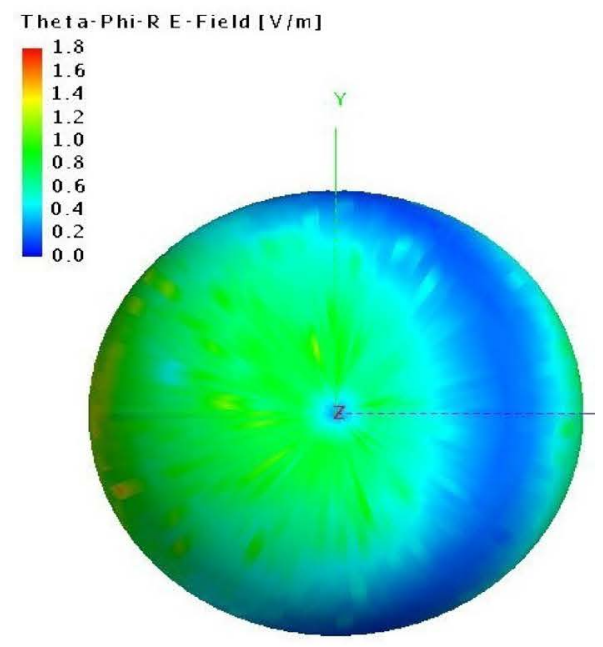

(a)

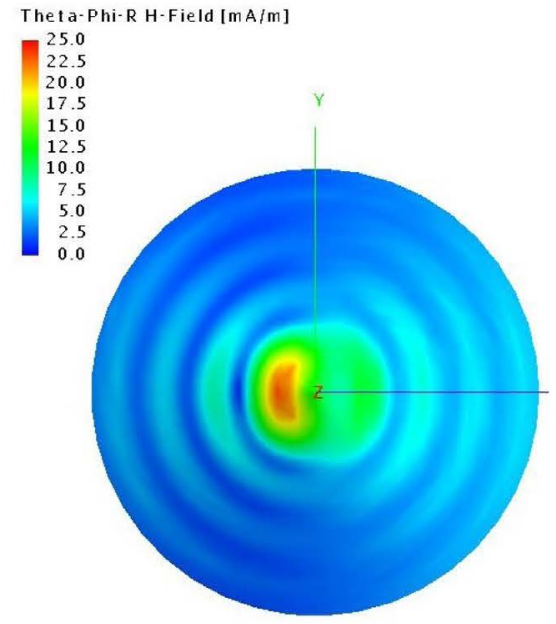

(b)

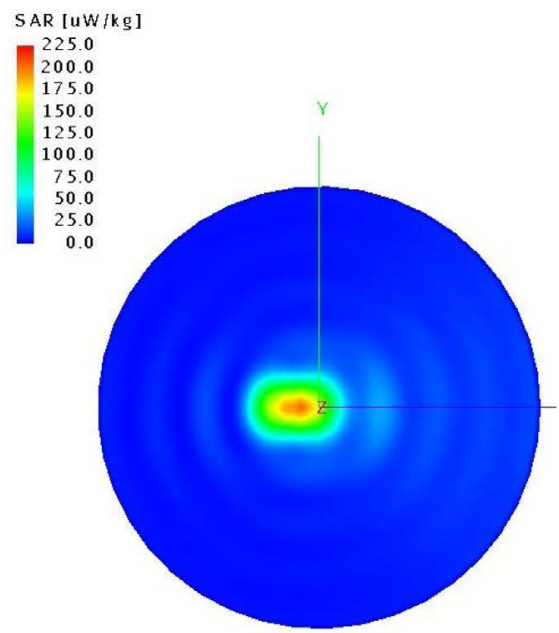

(c)

Figure 9. (a) Electric field distribution of PhiTheta-surface of water stored inside spherical-shaped container at $900 \mathrm{MHz}$; (b) Magnetic field distribution of PhiTheta-surface of water stored inside spherical-shaped container at $900 \mathrm{MHz}$; (c) Maximum SAR distribution of PhiTheta-surface of water stored inside spherical-shaped container at $900 \mathrm{MHz}$. 


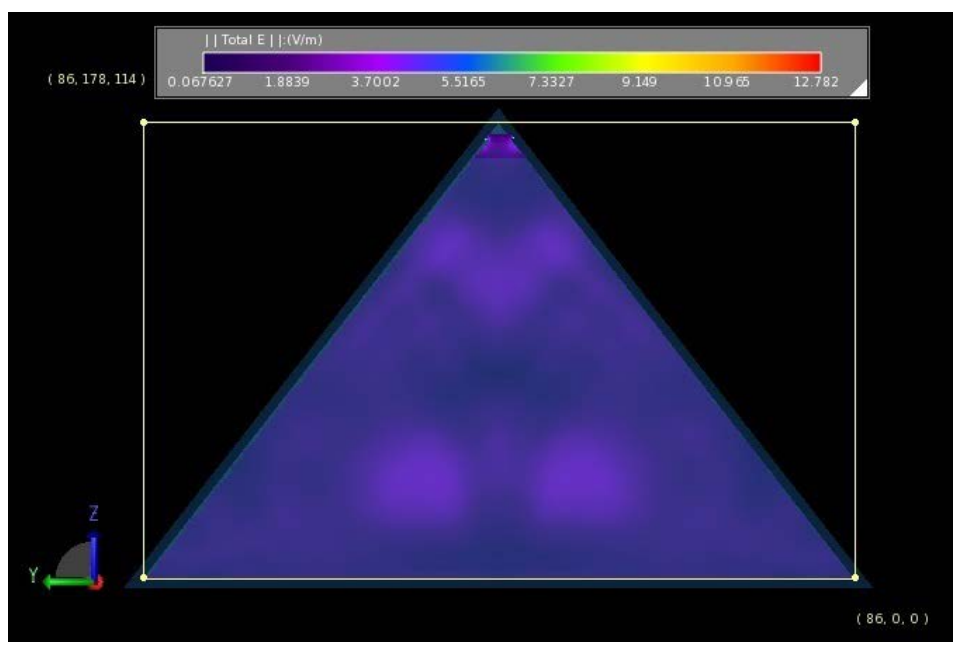

(a)

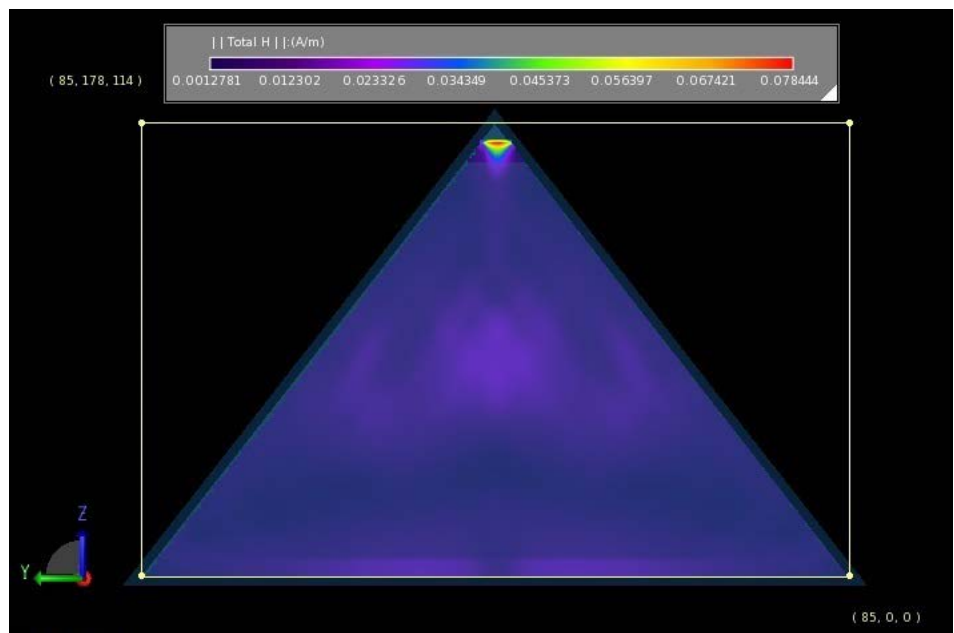

(b)

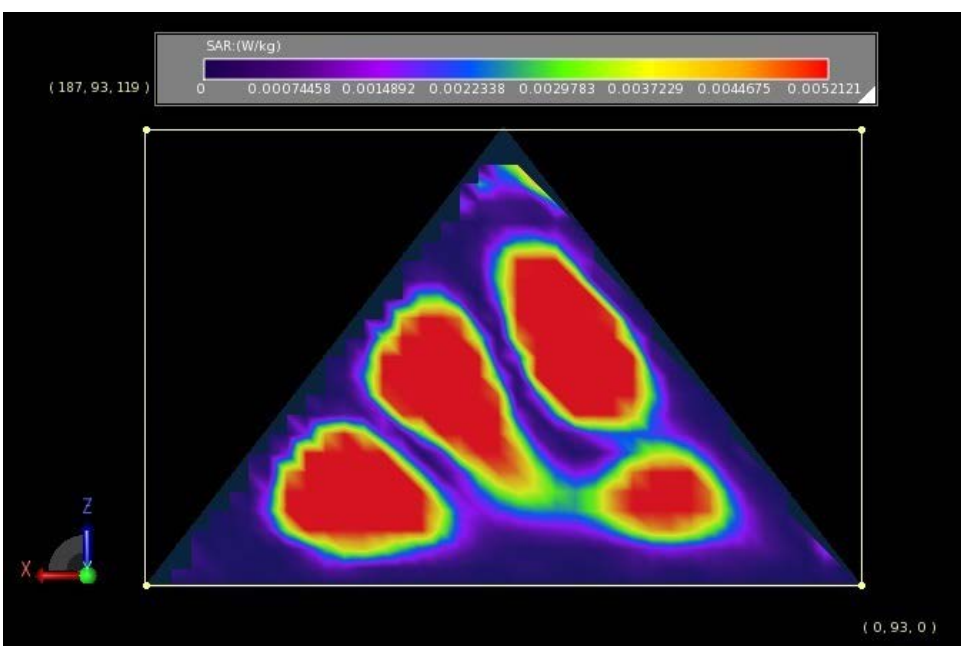

(c)

Figure 10. (a) Electric field distribution of yz surface of water stored inside pyramid-shaped container at $2400 \mathrm{MHz}$; (b) Magnetic field distribution of yz surface of water stored inside pyramid-shaped container at $2400 \mathrm{MHz}$; (c) Maximum SAR distribution of xz surface of water stored inside pyramid-shaped container at $2400 \mathrm{MHz}$. 


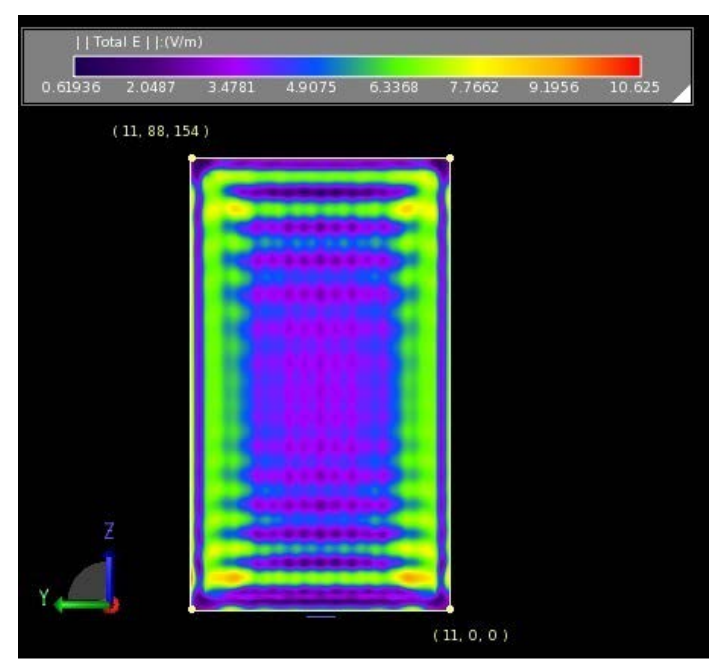

(a)

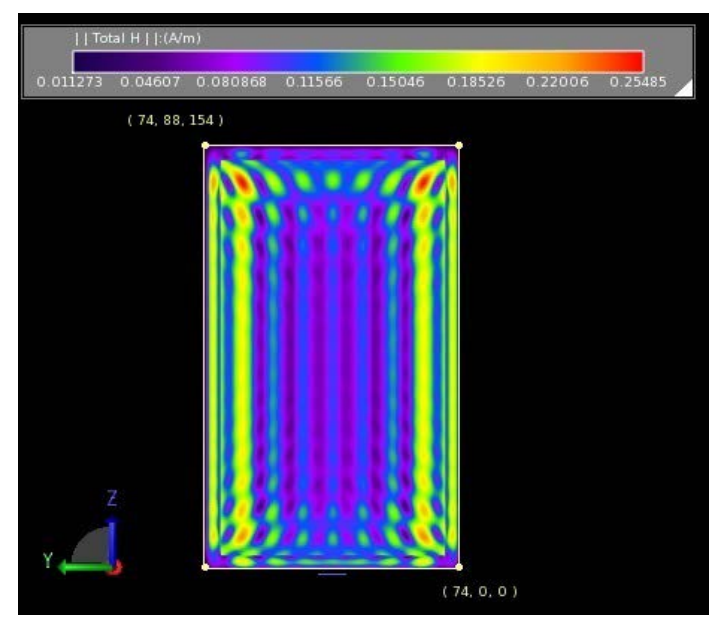

(b)

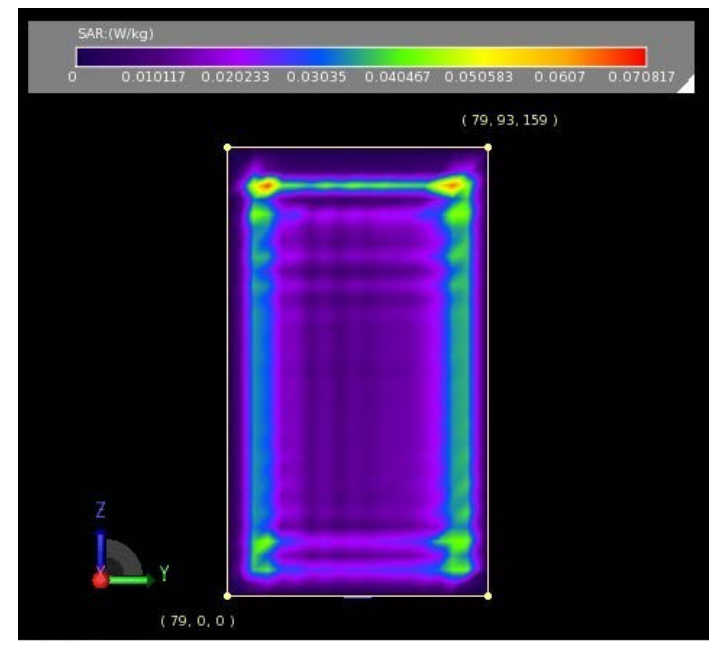

(c)

Figure 11. (a) Electric field distribution of yz surface of water stored inside rectangular-shaped container at $2400 \mathrm{MHz}$; (b) Magnetic field distribution of yz surface of water stored inside rectangular-shaped container at $2400 \mathrm{MHz}$; (c) Maximum SAR distribution of yz surface of water stored inside rectangular-shaped container at $2400 \mathrm{MHz}$. 


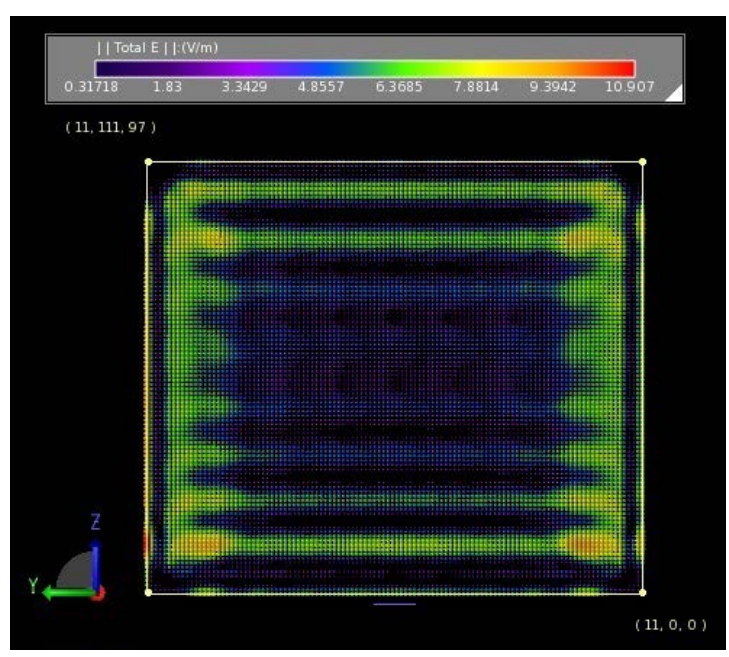

(a)

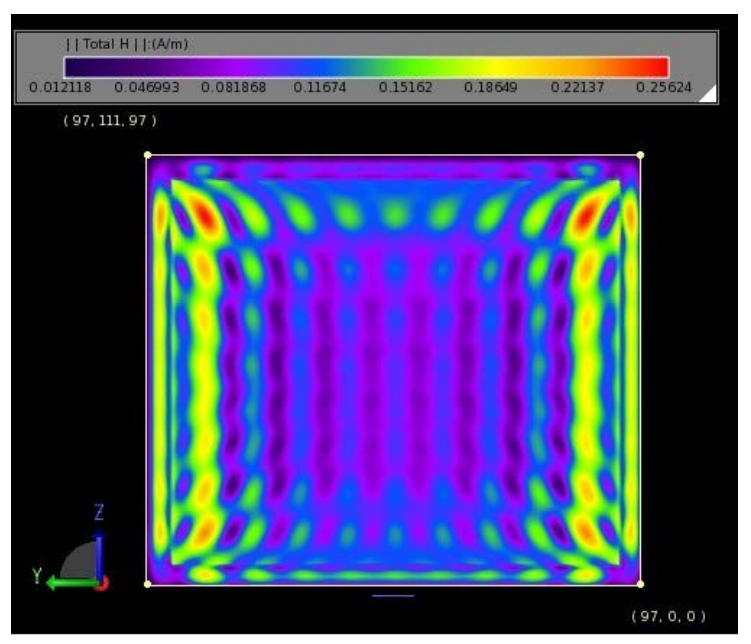

(b)

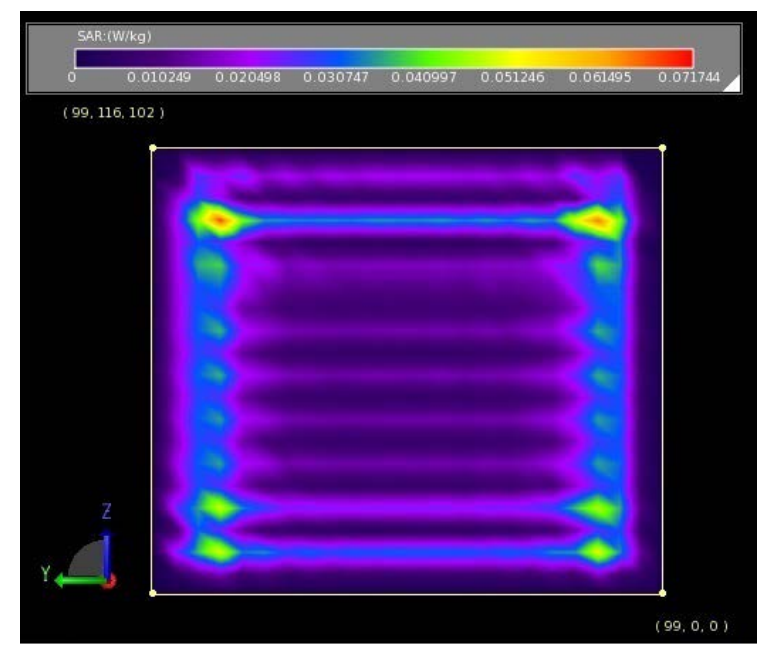

(c)

Figure 12. (a) Electric field distribution of yz surface of water stored inside square-shaped container at $2400 \mathrm{MHz}$; (b) Magnetic field distribution of yz surface of water stored inside square-shaped container at $2400 \mathrm{MHz}$; (c) Maximum SAR distribution of yz surface of water stored inside square-shaped container at $2400 \mathrm{MHz}$. 


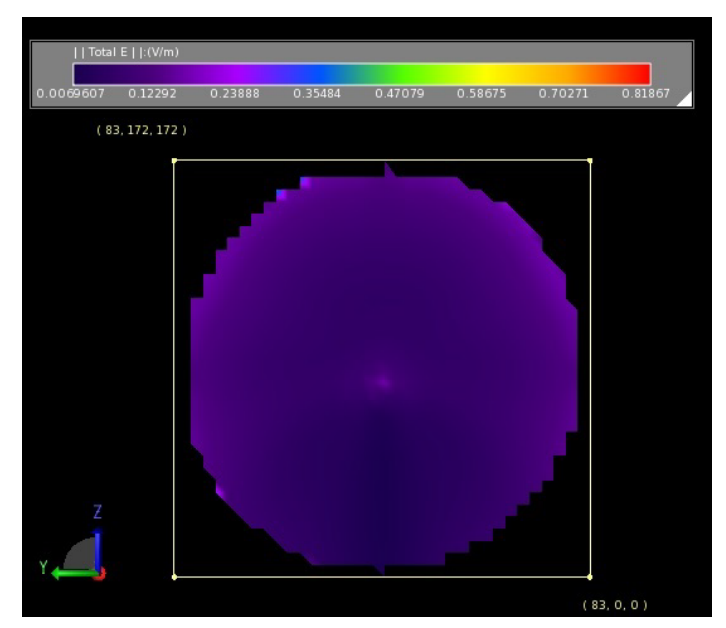

(a)

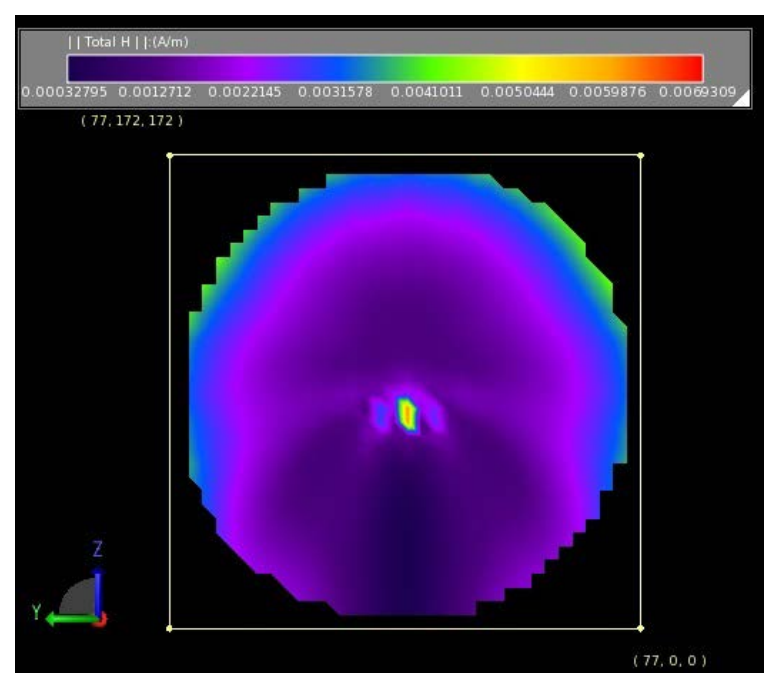

(b)

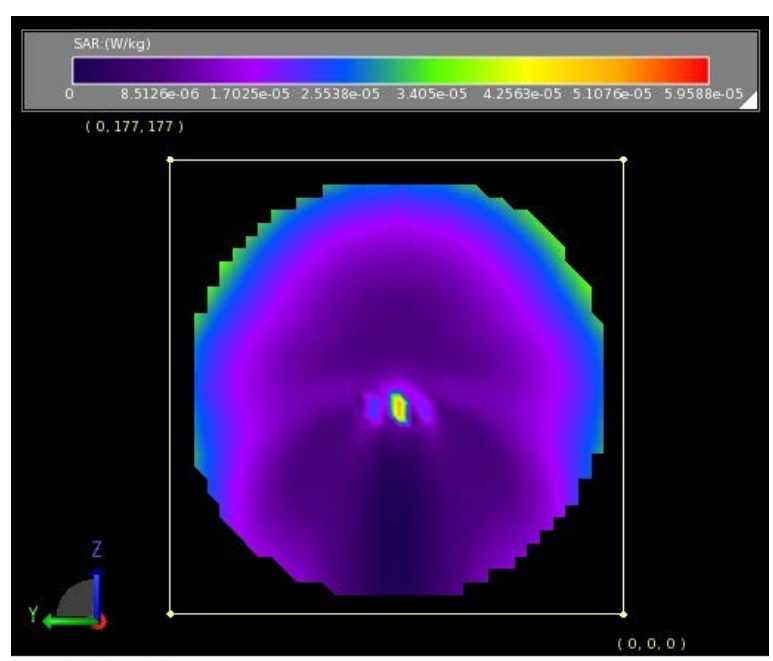

(c)

Figure 13. (a) Electric field distribution of yz surface of water stored inside spherical-shaped container at $2400 \mathrm{MHz}$; (b) Magnetic field distribution of yz surface of water stored inside spherical-shaped container at $2400 \mathrm{MHz}$; (c) Maximum SAR distribution of yz surface of water stored inside square-shaped container at $2400 \mathrm{MHz}$. 
electric and magnetic fields. The reduction of $\mathrm{pH}$, crystallization of mineral content of water, and prevention of microorganism growth associated with pyramidal-shaped containers observed during previous studies might have resulted from variations in the distribution of electric and magnetic fields, as well as the resulting increase of SAR.

This study provides several benefits: First, it will foster development of innovative packaging techniques by improving our understanding about the role packaging shape and dimension of materials play in enhancing absorption of energy from environmentally abundant electromagnetic fields. The relationship between the shape and dimension of packaging materials and the distribution of electric and magnetic fields, and the resulting SAR of stored materials will provide the groundwork for researchers to evaluate the effect of packaging shape on food and nutrition, cosmetics, pharmaceuticals, and other biological and nonbiological materials.

\section{Conclusion}

This research was carried out to evaluate the role of shape and dimensions of packaging materials in influencing the distribution of electric and magnetic fields and the resulting SAR induced in water caused by environmentally abundant electromagnetic radiation at 300, 900, and $2400 \mathrm{MHz}$. The study established that pyramidalshaped containers induce the highest levels of electric fields in stored water. In terms of influencing the distribution of electric fields, rectangular- and square-shaped container models retained the second and third positions, respectively. It can be concluded that that the shape and dimensions of packaging containers significantly influence the distribution of electric and magnetic fields caused by environmentally abundant electromagnetic radiation at 300, 900, and $2400 \mathrm{MHz}$; further studies should be conducted to evaluate how specific shapes or dimensions can affect distribution of electric and magnetic fields and resulting SAR by using different packaging materials in the EM simulation.

\section{Acknowledgements}

The authors would like to thank lectures, colleague and friends for giving valuable advices. We also wish to acknowledge Remcom Inc., USA for the trial license of XFDTD7 and for technical support.

\section{References}

[1] Shabani, H., Islam, M.R., Alam, A.H.M.Z. and El-Raouf, H.E.A. (2008) EM Radiation from Wi-LAN Base Station and Its' Effects in Human Body. ICECE 2008, International Conference on Electrical and Computer Engineering, Dhaka, 20-22 December 2008, 86-91.

[2] Cooper, J. and Hombach, V. (1996) Increase in Specific Absorption Rate in Human Heads Arising from Implantations. Electronics Letters, 32, 2217-2219. http://dx.doi.org/10.1049/el:19961507

[3] Whittow, W.G., Edwards, R.M., Panagamuwa, C.J. and Vardaxoglou, J.C. (2008) Effect of Tongue Jewellery and Orthodontist Metallic Braces on the SAR Due to Mobile Phones in Different Anatomical Human Head Models Including Children. Antennas and Propagation Conference, LAPC 2008, Loughborough, 17-18 March 2008, 293-296.

[4] Stergiou, K., Panagamuwa, C., Whittow, W. and Edwards, R. (2009) Effects of Metallic Semi-Rimmed Spectacles on SAR in the Head from a 900MHz Frontal Dipole Source. Antennas \& Propagation Conference, LAPC 2009, Loughborough, 16-17 November 2009, 721-724.

[5] Lazarescu, C., Nica, I. and David, V. (2011) SAR in Human Head Due to Mobile Phone Exposure. E-Health and Bioengineering Conference (EHB), Iasi, 24-26 November 2011, 1-4.

[6] Abidin, H.Z., Faruque, M.R.I., Islam, M.T. and Misran, N. (2011) Evaluation of SAR in the Human Head Due to Hand Ring Jewellery at 900 and $1800 \mathrm{MHz}$. 2011 IEEE International Conference on Space Science and Communication (IconSpace), Penang, 12-13 July 2011, 277-280.

[7] Hikage, T., Kawamura, Y., Nojima, T., Nagaoka, T. and Watanabe, S. (2013) Whole-Body Averaged SAR Measurements Using Cylindrical-External Field Scanning for 2 GHz Plane Wave Irradiation of Human Models. 2013 7th European Conference on Antennas and Propagation (EuCAP), Gothenburg, 8-12 April 2013, 1773-1774.

[8] Hosseinzadeh, R. and Zakeri, B. (2012) SAR of the Human's Head Due to Electromagnetic Radiation of a Mobile Antenna. 2012 20th Telecommunications Forum (TELFOR), Belgrade, 20-22 November 2012, 1159-1161.

[9] Mary, T.A.J., Ravichandran, C.S., Priyadarshini, S.J. and Sugumar, D. (2010) Investigation of SAR on Human Head Modelling Using Patch Antenna in Mobile Communication for Dual Band Frequency. 2010 International Conference on Emerging Trends in Robotics and Communication Technologies (INTERACT), Chennai, 3-5 December 2010, 121- 
124.

[10] Hirata, A., Fujiwara, O., Nagaoka, T. and Watanabe, S. (2010) Estimation of Whole-Body Average SAR in Human Models Due to Plane-Wave Exposure at Resonance Frequency. IEEE Transactions on Electromagnetic Compatibility, 52, 41-48. http://dx.doi.org/10.1109/TEMC.2009.2035613

[11] Lisheng, X., Meng, M.Q.H. and Chan, Y. (2009) Effects of Dielectric Parameters of Human Body on Radiation Characteristics of Ingestible Wireless Device at Operating Frequency of $430 \mathrm{MHz}$. IEEE Transactions on Biomedical Engineering, 56, 2083-2094. http://dx.doi.org/10.1109/TBME.2009.2021157

[12] Leung, S.W., Diao, Y., Chan, K.H., Siu, Y.M. and Wu, Y. (2012) Specific Absorption Rate Evaluation for Passengers Using Wireless Communication Devices Inside Vehicles with Different Handedness, Passenger Counts, and Seating Locations. IEEE Transactions on Biomedical Engineering, 59, 2905-2912. http://dx.doi.org/10.1109/TBME.2012.2210553

[13] Gosselin, M.C., Vermeeren, G., Kuhn, S., Kellerman, V., Benkler, S., Uusitupa, T.M.I., Joseph, W., Gati, A., Wiart, J., Meyer, F.J.C., Martens, L., Nojima, T., Hikage, T., Balzano, Q., Christ, A. and Kuster, N. (2011) Estimation Formulas for the Specific Absorption Rate in Humans Exposed to Base-Station Antennas. IEEE Transactions on Electromagnetic Compatibility, 53, 909-922. http://dx.doi.org/10.1109/TEMC.2011.2139216

[14] Zivkovic, Z., Despalatovic, D., Poljak, D., Sarolic, A. and El Khamlichi Drissi K. (2011) Assessment of SAR Distribution in the Human Eye and Pregnant Woman Models Exposed to RF Radiation Using FEKO Software Package. 2011 19th International Conference on Software, Telecommunications and Computer Networks (SoftCOM), Split, 15-17 September 2011, 1-5.

[15] Chen, H., Tang, J. and Liu, F. (2008) Simulation Model for Moving Food Packages in Microwave Heating Processes Using Conformal FDTD Method. Journal of Food Engineering, 88, 294-305. http://dx.doi.org/10.1016/j.jfoodeng.2008.02.020

[16] Geedipalli, S.S.R., Rakesh, V. and Datta, A.K. (2007) Modeling the Heating Uniformity Contributed by a Rotating Turntable in Microwave Ovens. Journal of Food Engineering, 82, 359-368. http://dx.doi.org/10.1016/j.jfoodeng.2007.02.050

[17] Resurreccion Jr., F.P., Tang, J., Pedrow, P., Cavalieri, R., Liu, F. and Tang, Z. (2013) Development of a Computer Simulation Model for Processing Food in a Microwave Assisted Thermal Sterilization (MATS) System. Journal of Food Engineering, 118, 406-416. http://dx.doi.org/10.1016/j.jfoodeng.2013.04.021

[18] Pitchai, K., Chen, J., Birla, S., Gonzalez, R., Jones, D. and Subbiah, J. (2014) A Microwave Heat Transfer Model for a Rotating Multi-Component Meal in a Domestic Oven: Development and Validation. Journal of Food Engineering, 128, 60-71. http://dx.doi.org/10.1016/j.jfoodeng.2013.12.015

[19] Liu, S., Fukuoka, M. and Sakai, N. (2013) A Finite Element Model for Simulating Temperature Distributions in Rotating Food during Microwave Heating. Journal of Food Engineering, 115, 49-62. http://dx.doi.org/10.1016/j.jfoodeng.2012.09.019

[20] Abdelsamie, M.A.A. (2014) Method and System for Energy Generation by Utilizing Environmentally Abundant Electromagnetic Fields. EG Patent Application No. 2014/781.

[21] Lisheng, X., Meng, M.Q.H., Hongliang, R. and Chan, Y. (2009) Radiation Characteristics of Ingestible Wireless Devices in Human Intestine Following Radio Frequency Exposure at 430, 800, 1200, and $2400 \mathrm{MHz}$. IEEE Transactions on Antennas and Propagation, 57, 2418-2428. http://dx.doi.org/10.1109/TAP.2009.2024459

[22] Jin, J. (1998) Electromagnetic Analysis and Design in Magnetic Resonance Imaging. Vol. 1, CRC Press, Boca Raton.

[23] Hardell, L. and Sage, C. (2008) Biological Effects from Electromagnetic Field Exposure and Public Exposure Standards. Biomedicine \& Pharmacotherapy, 62, 104-109. http://dx.doi.org/10.1016/j.biopha.2007.12.004

[24] Bernardi, P., Cavagnaro, M., Pisa, S. and Piuzzi, E. (2001) Power Absorption and Temperature Elevations Induced in the Human Head by a Dual-Band Monopole-Helix Antenna Phone. IEEE Transactions on Microwave Theory and Techniques, 49, 2539-2546. http://dx.doi.org/10.1109/22.971647

[25] Gandhi, O.P., Qing-Xiang, L. and Gang, K. (2001) Temperature Rise for the Human Head for Cellular Telephones and for Peak SARs Prescribed in Safety Guidelines. IEEE Transactions on Microwave Theory and Techniques, 49, 16071613. http://dx.doi.org/10.1109/22.942573

[26] Ticaud, N., Kohler, S., Jarrige, P., Duvillaret, L., Gaborit, G., O’Connor, R.P., Arnaud-Cormos, D. and Leveque, P. (2012) Specific Absorption Rate Assessment Using Simultaneous Electric Field and Temperature Measurements. IEEE Antennas and Wireless Propagation Letters, 11, 252-255. http://dx.doi.org/10.1109/LAWP.2012.2189748

[27] Murthy, K.D., George, M.C., Ramasamy, P. and Mustapha, Z.A. (2013) Housing under the Pyramid Reduces Susceptibility of Hippocampal CA3 Pyramidal Neurons to Prenatal Stress in the Developing Rat Offspring. Indian Journal of Experimental Biology, 51, 1070-1078.

[28] Abdelsamie, M.A.A., Rahman, R.B.A., Mustafa, S. and Hashim, D. (2013) Effect of Packaging Shape and Storage on 
the Keeping Quality of Mineral Water and a Development of Water-Treatment Device. Journal of Food Processing and Technology, 4, 231. http://dx.doi.org/10.4172/2157-7110.1000231

[29] Bhat, S., Rao, G., Murthy, K.D. and Bhat, P.G. (2009) Effect of Varying Durations of Pyramid Exposure-An Indication towards a Possibility of Overexposure. Indian Journal of Clinical Biochemistry, 24, 430-432. http://dx.doi.org/10.1007/s12291-009-0077-z

[30] Gopinath, R.K., Nagaraja, P.A. and Nagendra, H.R. (2008) The Effect of Pyramids on Preservation of Milk. Indian Journal of Traditional Knowledge, 7, 233-236.

[31] Bhat, M.S., Rao, G., Murthy, K.D. and Bhat, P.G. (2007) Housing in Pyramid Counteracts Neuroendocrine and Oxidative Stress Caused by Chronic Restraint in Rats. Evidence-Based Complementary and Alternative Medicine, 4, 35-42. http://dx.doi.org/10.1093/ecam/nel049

[32] Bhat, S., Rao, G., Murthy, K.D. and Bhat, P.G. (2007) Influence of Alignment of the Pyramid on Its Beneficial Effects. Indian Journal of Experimental Biology, 45, 455-458.

[33] Nayak, S., Rao, S.G., Murthy, K.D., Somayaji, S.N. and Bairy, K.L. (2003) Pyramid Environment Reduces the Wound Healing Suppressant Properties of Dexamethasone in Albino Rats. Indian Journal of Experimental Biology, 41, 645648.

[34] Narimanov, A.A. (2001) Pyramid Effect. Biofizika, 46, 951-957.

[35] Davidson, D. (1997) Shape Power. Rivas Publishing, Arizona.

[36] Flanagan, P. (1975) Pyramid Power. DeVorss \& Company, Camarillo.

[37] Abdelsamie, M.A., Rahman, R.A. and Mustafa, S. (2014) Pyramid Shape Power as a New Halal-Compliant Food Preservation and Packaging Technique. Procedia, Social and Behavioral Sciences, 121, 232-242. http://dx.doi.org/10.1016/j.sbspro.2014.01.1124

[38] Ruo, H.O. (1999) IEE Seminar on Electromagnetic Assessment and Antenna Design Relating to Health Implications of Mobile Phones (Ref. No. 1999/043). London, 7/1-7/5.

[39] Sullivan, D.M., Borup, D.T. and Gandhi, O.P. (1987) Use of the Finite-Difference Time-Domain Method in Calculating EM Absorption in Human Tissues. IEEE Transactions on Biomedical Engineering, BME-34, 148-157. http://dx.doi.org/10.1109/TBME.1987.326039

[40] Castro-Giráldez, M., Fito, P.J., Chenoll, C. and Fito, P. (2010) Development of a Dielectric Spectroscopy Technique for the Determination of Apple (Granny Smith) Maturity. Innovative Food Science \& Emerging Technologies, 11, 749754. http://dx.doi.org/10.1016/j.ifset.2010.08.002

[41] Fojt, L., Strašák, L., Vetterl, V. and Šmarda, J. (2004) Comparison of the Low-Frequency Magnetic Field Effects on Bacteria Escherichia coli, Leclercia adecarboxylata and Staphylococcus aureus. Bioelectrochemistry, 63, 337-341. http://dx.doi.org/10.1016/j.bioelechem.2003.11.010 